\title{
A method for real-time three-dimensional vector velocity imaging
}

\author{
Jensen, Jørgen Arendt; Nikolov, Svetoslav
}

Published in:

2003 IEEE Symposium on Ultrasonics Proceedings

Link to article, DOI:

10.1109/ULTSYM.2003.1293210

Publication date:

2003

Document Version

Publisher's PDF, also known as Version of record

Link back to DTU Orbit

Citation (APA):

Jensen, J. A., \& Nikolov, S. (2003). A method for real-time three-dimensional vector velocity imaging. In 2003 IEEE Symposium on Ultrasonics Proceedings (Vol. 2, pp. 1582-1585). IEEE. I E E E International Ultrasonics Symposium. Proceedings https://doi.org/10.1109/ULTSYM.2003.1293210

\section{General rights}

Copyright and moral rights for the publications made accessible in the public portal are retained by the authors and/or other copyright owners and it is a condition of accessing publications that users recognise and abide by the legal requirements associated with these rights.

- Users may download and print one copy of any publication from the public portal for the purpose of private study or research.

- You may not further distribute the material or use it for any profit-making activity or commercial gain

- You may freely distribute the URL identifying the publication in the public portal 


\title{
A Method for Real-Time Three-Dimensional Vector Velocity Imaging
}

\author{
Jørgen Arendt Jensen and Svetoslav Ivanov Nikolov \\ Center for Fast Ultrasound Imaging, Ørsted•DTU, Bldg. 348, \\ Technical University of Denmark, DK-2800 Kgs. Lyngby, Denmark
}

\begin{abstract}
The paper presents an approach for making real-time three-dimensional vector flow imaging. Synthetic aperture data acquisition is used, and the data is beamformed along the flow direction to yield signals usable for flow estimation. The signals are cross-correlated to determine the shift in position and thereby velocity. The data can be beamformed after reception in any direction and any vectorial velocity can be found. More than 60 independent velocity volumes can be made per second with this approach.
\end{abstract}

A $3 \mathrm{MHz} 2 \mathrm{D}$ matrix transducer consisting of $64 \times 64$ elements with $\lambda / 2$ pitch is used. The emissions are done using 16 $\mathrm{x} 16=256$ elements at a time, and the received signals from the same elements are sampled. Access to the individual elements is done through 16-to-1 multiplexing, so that only a 256 channel transmitting and receiving system is needed.

The method has been investigated using Field II. Parabolic flow in a $10 \mathrm{~mm}$ radius vessel inclined at 60 degrees to the acoustical axis of the transducer was simulated. The mean standard deviation of the estimates was $0.0098 \mathrm{~m} / \mathrm{s}$ over the whole vessel cross-section, which is $3.3 \%$ relative to the peak velocity. The bias was $0.023 \mathrm{~m} / \mathrm{s}(7.5 \%)$. False peaks were found mainly at the edges of the vessel due to the echocanceling, and the probability of false detection was $2.2 \%$.

\section{INTRODUCTION}

One of the major problems of conventional ultrasound systems is that they only show a cross-sectional 2D image of the body, whereas the structures to image are three-dimensional. This problem has been addressed by many manufactures by making manually sweeping 3D scans, that can assemble data for a full volume. These systems are often cumbersome to use and any kind of motion will distort the image volume and potentially make it useless. It also precludes visualization of moving structures and real time imaging cannot be made, which removes one of the major advantages of ultrasound imaging.

Methods based on parallel beamforming has therefore been developed. The system made at Duke University $[1,2]$ uses a matrix transducer and parallel beamformation to generate 16 receive beams from one emission. The frame rate can then be maintained at 15 volumes per second, which is sufficient to visualize the moving heart. The acquisition rate is, however, not sufficient for generating flow images. Here 8 to 16 emissions must be made per direction in order to estimate the velocity, and this yield an unacceptable frame rate of 1 to 2 volumes per second for a full 3D volume. Alternative approaches are, thus, needed for generating a full 3D flow images.

A promising approach is synthetic aperture (SA) imaging. Here few elements are used in transmit, and signals from all elements in the receiving aperture can be measured by selecting different receive elements through multiplexing. The approach can yield dynamically focused images in both transmit and receive and the frame rate can be made very high.

Several authors have investigated SA imaging and has shown the benefits of the approach $[3,4,5,6]$. Lockwood et al. $[7,8]$ described a real time 3D SA system, which used a rocking phased array system. The system can, however, not be used for flow imaging, due to the physical motion of the array. For a fixed array it is possible to use a recursive SA method for generating flow images $[9,10]$. The approach can be generalized to three dimensions using a $2 \mathrm{D}$ array, and this is the method studied in this paper.

The major problem is devising such a system is how to handle the many elements of the 2D array transducer, and which elements to use. This is solved in the paper through multiplexing. The full aperture is sampled by using a 16 to 1 multiplexing and the number of active elements are hereby 256 for a $64 \times 64$ array. In Section II the basic approach is described and the velocity estimation is detailed in Section III. The performance of the approach is determined through simulations described in Section IV and the results from this are given in Section V.

\section{SyNTHETIC APERTURE FLOW ESTIMATION}

A synthetic aperture image is made from a number of emissions. A pulse is emitted from a single or group of elements to form a spherical wave. Signals are then received on all elements and a low resolution image is formed. A new emission is made from a new point on the aperture, and the received signals are combined with the previous emission to make an image. A high resolution image is finally formed, when emis- 
sions have been made over the full aperture. A synthetic aperture image is, thus, acquired simultaneously in all directions over a number of emissions compared to the normal sequential image acquisition. This changes the way flow imaging is done.

It was demonstrated in [9] that synthetic aperture data can be used for velocity estimation. The underlying principle is that motion can be determined by comparing two measurements acquired at two different times. The key point is that the acquisitions must have been made using the same emissions and receive beamforming. The basic method acquires a full high resolution image and then a subsequent high resolution image is acquired. Data from these two images are correlated and the velocity found. It is also possible to continuously acquire high resolution images, so that data suitable for velocity estimation is continuously available.

\section{3D FLOW IMAGING}

The major problem in making a three-dimensional ultrasound image using a 2D array is the many transducer elements in the array and the scanning of the many lines in the volume. Both problems can be solved using synthetic aperture imaging.

Different elements can be sampled at the different emissions using multiplexing. Hereby the full 2D aperture can be covered over the $N$ emissions for creating the full high resolution image. The number of active receive channels $N_{r}$ must be

$$
N_{r}=N_{x} N_{y} / N
$$

where $N_{x}$ is the number of rows and $N_{y}$ the number of columns in the $2 \mathrm{D}$ array. A $64 \times 64$ arrays, thus, needs 256 receiving channels, when $N=16$.

The allocation of elements for such a sequence is shown in Fig. 1. The numbers indicates the emission number in the sequence, and the block of elements used for each emission. They each consist of $16 \times 16=256$ elements, for which a spherical wave is formed in transmit. The same elements are also used in receive. For the next emission the multiplexers are positioned for block 2 and so forth. Measuring the signals from the elements for the full 16 emissions then cover the full aperture, and a high resolution image can be formed.

The received data is beamformed in direction of the velocity vector as described in [11]. The moving scatterers are then tracked along the flow direction, and the velocity magnitude is directly found. This is done by cross-correlating data from one high resolution image with the next high resolution image. The peak in the cross-correlation function is then located at the distanced traveled between emissions given by

$$
D_{m}=\left|\vec{v} T_{p r f} N\right|
$$

where $\vec{v}$ is the velocity and $T_{p r f}$ is the time between two emissions.

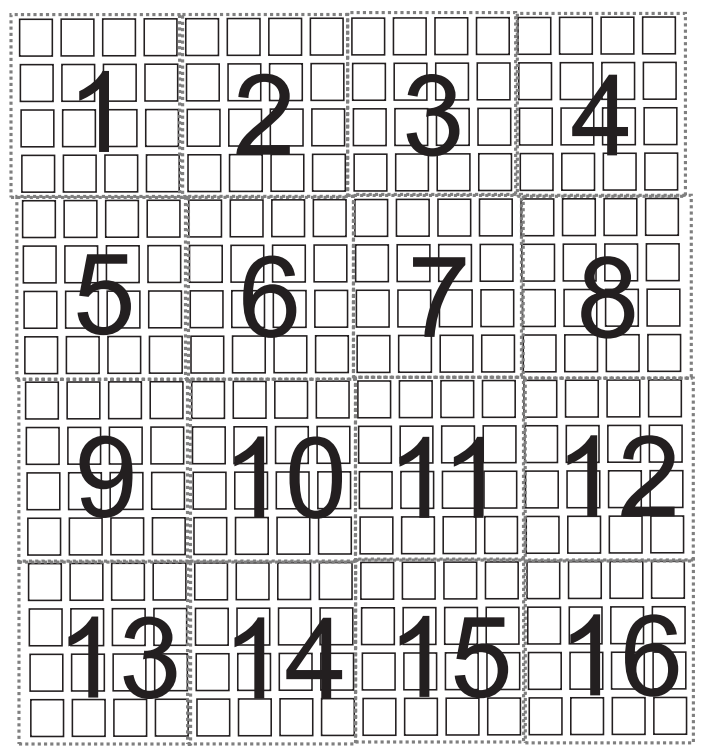

Figure 1: Allocation of elements for multiplexing and emission. The numbered blocks of elements are used for each emission. Only a 16 by 16 element array is shown here for clarity.

The cross-correlation function can be found for every emission using recursive imaging. A cross-correlation can be made between high resolution image number $n$ and $n+N$, and the location of the peak will be at the same location as for $n+1$ and $n+1+N$, if the velocity stays constant. The cross-correlations can then be directly added and the accuracy of the velocity estimate is hereby improved [11].

\section{Simulation METHOD}

The performance of the velocity estimation method has been investigated using the Field II program [12, 13]. It uses spatial impulse responses to describe the ultrasound field and can be used for all transducer geometries, focusing and apodization schemes, and excitations. The received signals on the individual transducer elements are found from the summation of responses from a random collection of point scatterers.

The simulation is performed for every pulse emission, and the point scatterers are then propagated between pulse emissions according to the spatial velocity field. The flow is assumed laminar and parabolic with a velocity distribution of

$$
v(r)=v_{0}\left(1-\left(\frac{r}{R}\right)^{2}\right),
$$

where $r$ is the radial position in the vessel, $v_{0}$ is the peak velocity at the center, and $R$ is vessel radius. The propagation of the position $\vec{r}(t)$ of the individual scatterers is given by

$$
\vec{r}\left(t+T_{p r f}\right)=\vec{r}(t)+\vec{v}(\vec{r}(t)) T_{p r f},
$$




\begin{tabular}{|l|c|c|}
\hline Center frequency & $f_{0}$ & $3 \mathrm{MHz}$ \\
\hline Speed of sound & $c$ & $1540 \mathrm{~m} / \mathrm{s}$ \\
\hline Wavelength & $\lambda=c / f_{0}$ & $0.51 \mathrm{~mm}$ \\
\hline Element pitch & $w$ & $\lambda / 2$ \\
\hline Element height & $h_{e}$ & $0.23 \mathrm{~mm}$ \\
\hline Element width & $h_{e}$ & $0.23 \mathrm{~mm}$ \\
\hline Kerf & $k_{e}$ & $30 \mu \mathrm{m}$ \\
\hline Number of elements & $N_{x} \times N_{y}$ & $64 \times 64$ \\
\hline Active elements & $N_{a_{x}} \times N_{a_{y}}$ & $16 \times 16$ \\
\hline \hline Emissions for estimation & $N$ & 128 \\
\hline Sampling frequency & $f_{s}$ & $100 \mathrm{MHz}$ \\
\hline Pulse repetition frequency & $f_{p r f}$ & $7.7 \mathrm{kHz}$ \\
\hline Distance between estimates & $d z$ & $0.5 \mathrm{~mm}$ \\
\hline Sampling interval for lines & $d x=\lambda / 20$ & $0.026 \mathrm{~mm}$ \\
\hline Correlation interval & $-10 \lambda: 10 \lambda$ & $-2.6: 2.6 \mathrm{~mm}$ \\
\hline \hline Radius of vessel & $R$ & $10 \mathrm{~mm}$ \\
\hline Distance to vessel center & $Z_{v e s}$ & $40 \mathrm{~mm}$ \\
\hline Peak velocity in flow & $v_{0}$ & $0.3 \mathrm{~m} / \mathrm{s}$ \\
\hline
\end{tabular}

Table 1: Standard parameters for transducer and parabolic flow simulation.

where $\vec{r}(t)$ is the position of the scatterer at time $t$.

The parameters for the simulation is shown in Table 1. Parabolic flow in a $10 \mathrm{~mm}$ radius vessel inclined at $60 \mathrm{de}-$ grees to the acoustical axis of the transducer was simulated using 50,000 point scatterers. The vessel's peak velocity was $0.3 \mathrm{~m} / \mathrm{s}$, the pulse repetition frequency $7.7 \mathrm{kHz}$ and $800 \mathrm{emis}-$ sions were simulated. The received signal of the 256 active elements were found individually, and stored in files for later beamformation.

\section{Results}

A defocused field is emitted and a circular Hamming apodization is applied on the transmitting elements. A total of 16 emissions is made to cover the full aperture and acquire data from all 4096 elements. Eight groups of 16 emissions were used for making beams for the velocity estimation, and 6 independent cross-sectional flow images in the azimuth-axial direction could be made from the 800 simulated emissions. Data was formed in lines along the flow using the last 16 emissions to generate a high resolution directional signal. All signals with the same emission order were then used in stationary echo canceling to make the processing as realistic as possible. This was done by finding the mean value over all the signals and then subtracting this signal from the directional signals.

Data from the first 16 emission was then cross-correlated with data from the next 16 emissions. The cross-correlation function was then averaged for 128 emissions, and the loca-

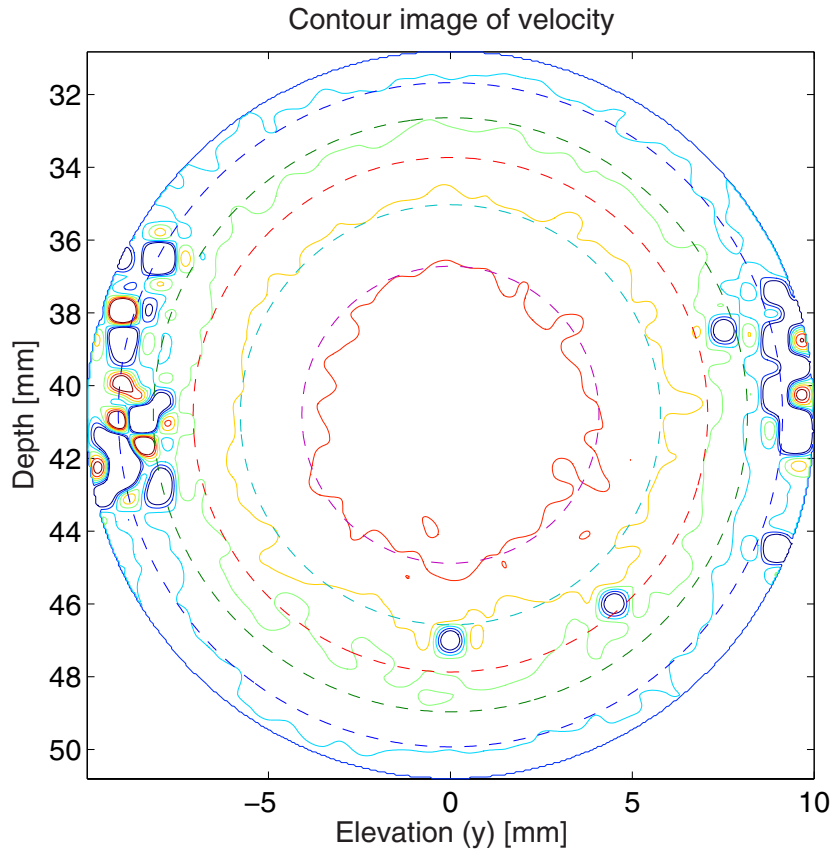

Figure 2: Velocity contours for a parabolic profile. The solid lines are the velocity estimates and the dashed lines are the true velocity. There is $0.05 \mathrm{~m} / \mathrm{s}$ between contours.

tion of the peak value, and thereby the velocity, was found. Velocity estimates were found for every $0.5 \mathrm{~mm}$ in the depth and elevation direction and the directional signals had a length of $20 \lambda$ with a spatial sampling distance of $d x=\lambda / 20$. The angle for the beamformation was input to the routine, but could also be determined from the B-mode volume image. Using this approach 60 velocity vector volumes to a depth of $10 \mathrm{~cm}$ can be made per second.

Six cross-sectional velocity images were found from the simulated data. An example is shown in Fig. 2, which shows a contour plot of the velocity estimates as the solid lines and the true velocity is shown as the dashed lines. There is 0.05 $\mathrm{m} / \mathrm{s}$ between contours. The corresponding color flow image of the magnitude is shown in Fig. 3.

From Fig. 2 is can be seen that the correct velocity magnitude can be estimated. At certain places the cross-correlation function finds an incorrect peak, but it is sufficiently rare, that it can be corrected with a suitable algorithm.

The performance has been found from all 6 independent images. The estimates were compared to the true velocity and the standard deviation was found within the vessel radius. Estimates with a deviation beyond 5 standard deviations were characterized as false peaks and were removed form the determination of the standard deviation. The mean standard deviation of the estimates was $0.0098 \mathrm{~m} / \mathrm{s}$ over the whole vessel cross-section, which is $3.27 \%$ relative to the peak velocity of $0.3 \mathrm{~m} / \mathrm{s}$. The bias was $0.023 \mathrm{~m} / \mathrm{s}(7.54 \%)$. False peaks 


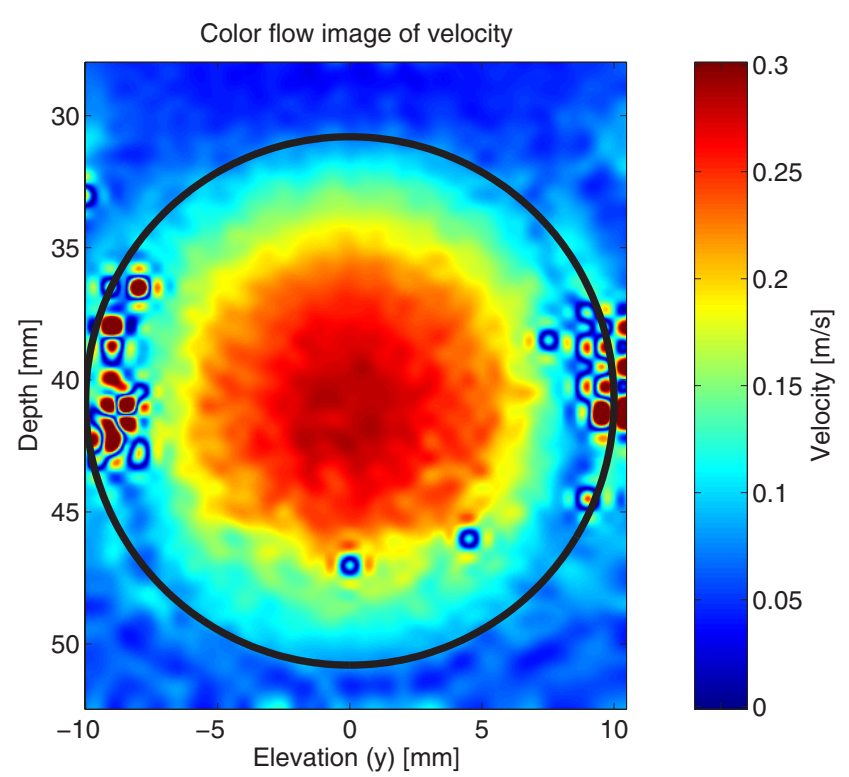

Figure 3: Cross-sectional velocity image created from the synthetic aperture data. The color bar shows the velocity in $\mathrm{mm} / \mathrm{s}$. The black line shows the circumference of the vessel.

were found mainly at the edges of the vessel due to the echocanceling, and the probability of false detection was $2.16 \%$.

\section{CONCLUSION}

The method presented can yield velocity estimate for a full three-dimensional volume at a rate of 60 volumes per second with a standard deviation of $3.27 \%$. The correct velocity magnitude can potentially be found for any velocity direction, when the flow angle is inserted into the routine. The approach uses a 64 x 64 element array connected to a 16-to-1 multiplexer. Using synthetic aperture imaging only makes it necessary to use 256 active transmit and receive channels at the same time, and the amount of electronics for data acquisition can therefore be kept at a level of a modern high end scanner.

No noise or other artifacts were introduced into the simulation. The performance will therefore be degraded in a real system, where chirp excitation should be used to increase the signal-to-noise ratio. Only one method for assigning the elements for emission and reception on the aperture was investigated. It is quite possible that other assignments will lead to better results, if the transmitting and receiving elements where arranged in another pattern.

\section{ACKNOWLEDGEMENT}

This work was supported by grant 9700883,9700563 and 26-01-0178 from the Danish Science Foundation and by B-
K Medical A/S, Denmark.

\section{REFERENCES}

[1] S. W. Smith, H. G. Pavy, and O. T. von Ramm. Highspeed ultrasound volumetric imaging system - Part I: Transducer design and beam steering. IEEE Trans. Ultrason., Ferroelec., Freq. Contr., 38:100-108, 1991.

[2] O. T. von Ramm, S. W. Smith, and Henry G. Pavy. High-speed ultrasound volumetric imaging system Part II: Parallel processing and image display. IEEE Trans. Ultrason., Ferroelec., Freq. Contr., 38:109-115, 1991.

[3] J. T. Ylitalo and H. Ermert. Ultrasound synthetic aperture imaging: monostatic approach. IEEE Trans. Ultrason., Ferroelec., Freq. Contr., 41:333-339, 1994.

[4] J. T. Ylitalo. On the signal-to-noise ratio of a synthetic aperture ultrasound imaging method. Eur. J. Ultrasound, pages 277-281, 1996.

[5] M. Karaman, P. C. Li, and M. O'Donnell. Synthetic aperture imaging for small scale systems. IEEE Trans. Ultrason., Ferroelec., Freq. Contr., 42:429-442, 1995.

[6] S. Holm and H. Yao. Improved framerate with synthetic transmit aperture imaging using prefocused subapertures. In Proc. IEEE Ultrason. Symp., pages 15351538, 1997.

[7] G. R. Lockwood, J. R. Talman, and S. S. Brunke. Realtime 3-D ultrasound imaging using sparse synthetic aperture beamforming. IEEE Trans. Ultrason., Ferroelec., Freq. Contr., 45:980-988, 1998.

[8] C. R. Hazard and G. R. Lockwood. Theoretical assessment of a synthetic aperture beamformer for real-time 3-D imaging. IEEE Trans. Ultrason., Ferroelec., Freq. Contr., 46:972-980, 1999.

[9] S. I. Nikolov and J. A. Jensen. Velocity estimation using synthetic aperture imaging. In Proc. IEEE Ultrason. Symp., pages 1409-1412, 2001.

[10] S. I. Nikolov and J. A. Jensen. In-vivo synthetic aperture flow imaging in medical ultrasound. IEEE Trans. Ultrason., Ferroelec., Freq. Contr., pages 848-856, 2003.

[11] J. A. Jensen and S. I. Nikolov. Transverse flow imaging using synthetic aperture directional beamforming. In Proc. IEEE Ultrason. Symp., pages 1488-1492, 2002.

[12] J. A. Jensen and N. B. Svendsen. Calculation of pressure fields from arbitrarily shaped, apodized, and excited ultrasound transducers. IEEE Trans. Ultrason., Ferroelec., Freq. Contr., 39:262-267, 1992.

[13] J. A. Jensen. Field: A program for simulating ultrasound systems. Med. Biol. Eng. Comp., 10th NordicBaltic Conference on Biomedical Imaging, Vol. 4, Supplement 1, Part 1:351-353, $1996 \mathrm{~b}$. 